\title{
Clinical Evaluation of the Sensitivity and Induced Pain Pattern on Passive Straight Leg Raisng Test in Patients with Lumbosacral Root Pain
}

\author{
Dr. Ali Abdul-Rahman Younis ${ }^{a}$, Dr. Ali F. Y. Al-Barodchi ${ }^{b}$, Dr. Wameedh R.S. Al-Omari ${ }^{a}$ \\ ${ }^{a}$ Department of Internal Medicine, College of Medicine, University of Mosul, Mosul, ${ }^{b}$ The Rheumatology Outpatient Clinic, Ibn \\ Sena Teaching Hospital, Mosul, Iraq. Correspondence: Ali Abdul-Rahman Younis. ali.younis7622@yahoo.com.
}

(Ann Coll Med Mosul 2019; 41 (1):69-74).

Received: $15^{\text {th }}$ Jan. 2019; Accepted: $2^{\text {nd }}$ Jun. 2019.

\section{ABSTRACT}

Background: The straight leg raising test (SLR) is widely used to evaluate patients with sciatica. The SLR was evaluated in many previous studies; however, there is no agreement about the characterization of the test.

Objective: To investigate the patterns of pain on passive SLR in patients with sciatica and to evaluate the effects of various maneuvers on this test.

Study design: Case series study.

Setting: Rheumatology division, Ibn Sinna Teaching Hospital, Mosul, IRAQ.

Methodology: Seventy patients with unilateral sciatica for less than 2 years duration, there ages are between 20 to 50 years, were studied. A detailed history was obtained from the patients and they were subjected to full physical examination for their current problem. The SLR was performed, the angle of elevation was recorded and the effect of ankle dorsiflexion and maximal neck flexion was evaluated. After that, the SLR repeated but with lumbar flexion, the angle of the SLR was also recorded. Then crossed SLR was performed.

Results: SLR was positive in $91.4 \%$ of cases. Ankle augmentation was positive in $95.3 \%$ of cases, while neck flexion increased pain in $28.1 \%$ only. Cross SLR test was positive in $17.1 \%$ of cases. Increased SLR angle by contralateral hip flexion was seen in $81.3 \%$ of cases; mean SLR angle with the contralateral hip extension was $47.8 \pm 12.4$ degree, while contralateral hip flexion increased the mean SLR angle to $58.9 \pm 16.9$ degree. The patterns of pain induced by SLR were: low back pain only in $50 \%$ of cases, leg pain only in $42.1 \%$ of cases, low back and leg pain in $7.9 \%$ only.

Conclusion: The patterns of pain that were induced by passive SLR were: low back pain only, leg pain only, low back and leg pain. This could bear relation to the position of the prolapsed disc.

The use of sensitizing maneuvers (ankle dorsiflexion, neck flexion) increases pain in patients with sciatica with positive SLR test, so we recommend the conduction of these maneuvers in patients with positive SLR. Measurement of SLR was influenced by the position of the contralateral hip (flexed Vs. extended).

Keywords: Low Back Pain, Sciatica, Straight Leg Raising Test.

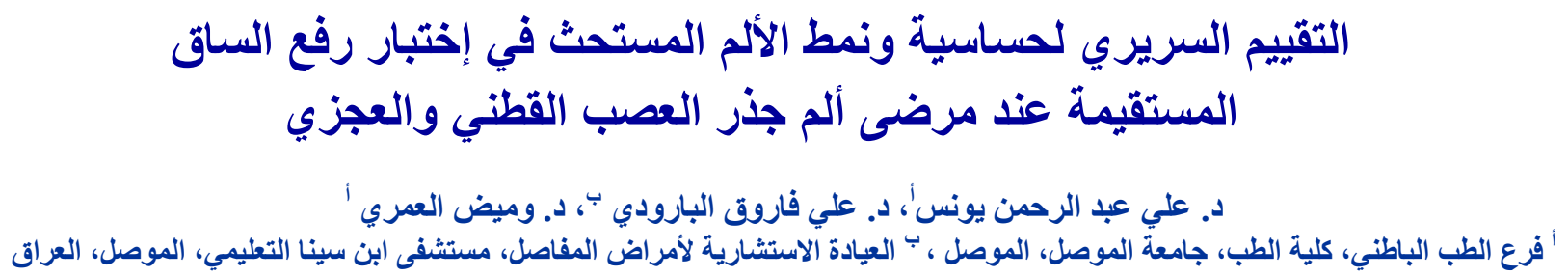


الخلاصة الخلفية: يستخدم إختبار رفع الساق المستقيمة بصورة واسعة لتقييم حالة المرضى الذين يعانون من عرق النسا. وقد تم تقييم

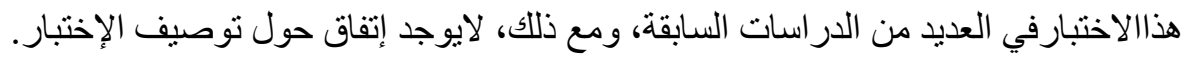

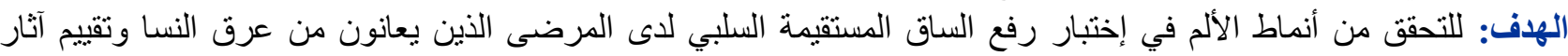
مناور ات مختلفة في هذا الإختبار.

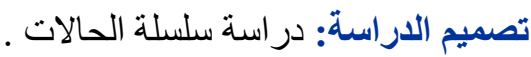

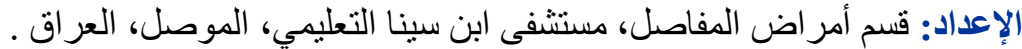

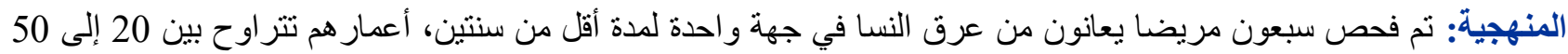

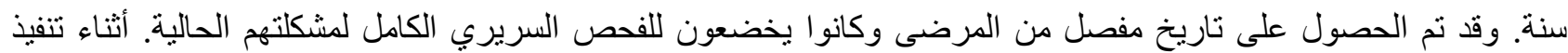

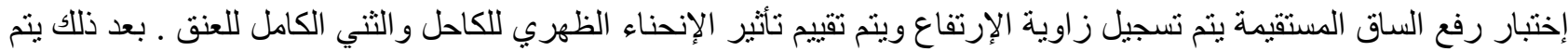

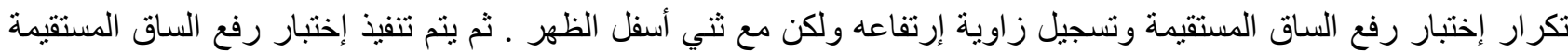

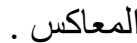
النتائج: كان إختبار رفع الساق المستقيمة إيجابيا في 91.4 ٪ من الحالات. تقوية الإختبار بواسطة الثني الظهري للكاحل كان

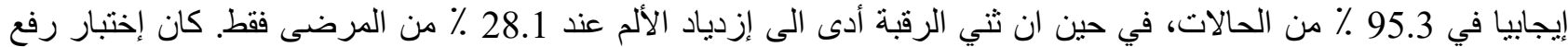

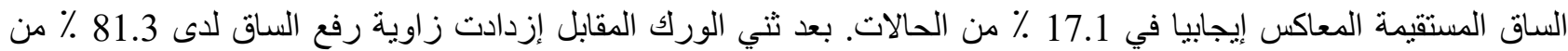

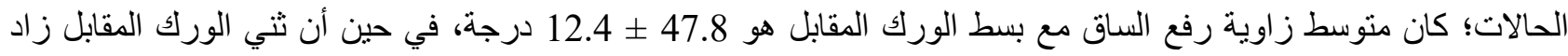

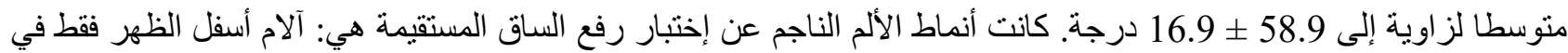
50٪ من الحالات، ألم في الساق فقط في 42.1 \%

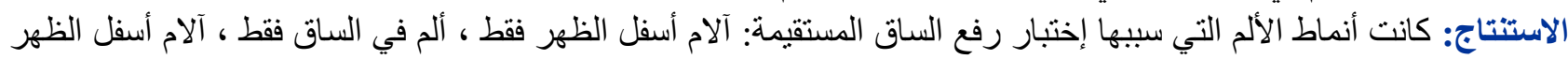

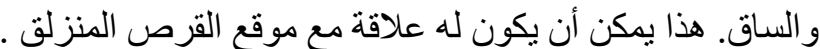

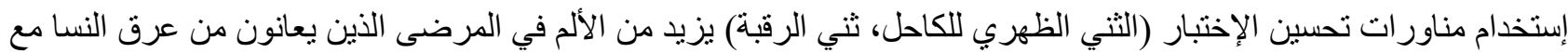

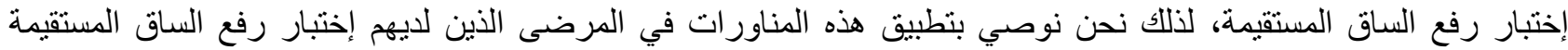

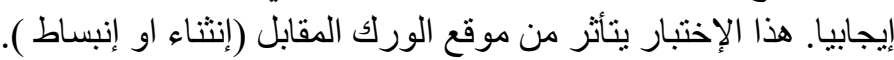

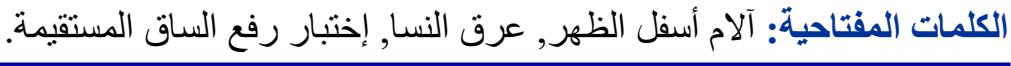

\section{INTRODUCTION}

$S$ ciatica is defined as radiating pain that follows $\checkmark$ the distribution of lumbar nerve roots ${ }^{1}$. It affects about $5-10 \%$ of patients with low back pain ${ }^{2}$. It may be accompanied by neurological dysfunction, such as weakness and numbness ${ }^{3}$. The diagnosis of Sciatica is based mainly on history taking and physical examination ${ }^{2}$. The straight leg raising test (SLR) is the most commonly applied diagnostic test used to evaluate patients with sciatica ${ }^{4}$, and it is considered to have high sensitivity but low specificity ${ }^{5}$. The estimated sensitivity and specificity of SLR is $91 \%$ and $26 \%$ respectively ${ }^{4}$.

The SLR test is done by passive elevation of the leg on the symptomatic side with the patient in the supine position ${ }^{5}$; however, there is no agreement about the characterization of the test especially the site of pain which is considered a positive test. Many previous reports considered below knee pain as a positive SLR test ${ }^{5,6}$. In another study, the SLR was considered positive if it produced lower extremity pain and/or back pain ${ }^{7}$. Urban in its review article reported SLR to be positive when it caused pain anywhere ${ }^{8}$.

The use of structural differentiation during SLR test is of crucial importance in the successful interpretation of the test. Flexion of the cervical spine and dorsiflexion of the ankle are some examples of structural differentiating maneuvers ${ }^{9}$.

Therefore this study was designed to investigate the patterns of pain on passive SLR in patients with sciatica and to evaluate for the effect of various maneuvers on this test.

\section{SUBJECTS AND METHODS}

The present study had approval from the scientific research committee of Mosul health directorate, Mosul- Iraq. 
Inclusion criteria: Patients with unilateral sciatica Exclusion criteria:

1- Systemic manifestations.

2- Suspicion of neoplastic or infective spinal conditions.

3- Compression fractures.

4- Major trauma or past spinal surgery.

5- Chronic inflammatory joint/spinal diseases.

6- Spondylolisthesis.

7- Specific neurological problems (stroke, multiple sclerosis, peripheral neuropathy).

8- Steroids for more than 3 months.

9- Diabetes.

10- Pregnancy.

\section{Subjects}

Seventy patients participated in this case series collection study, whose ages were range from 20 to 50 years, and they were suffering from unilateral sciatica for less than 2 years duration with or without low back pain (LBP).

\section{Methods}

A detailed history was obtained from the patients and they were divided into three groups: acute (those with pain less than 6 weeks), subacute (from 6-12 weeks) and chronic (when the pain lasting more than 12 weeks) ${ }^{10}$.

The patients then subjected to full physical examination for their current problem, including observation of the patient gait, assessment of the range of motion of the lumbar spine.

The straight leg raising test (SLR) was performed in the supine position with the knee in full extension, the examiner put one hand on the patient's knee to keep it extended and the other hand under the heel, then slowly raises the patient's leg until pain is produced anywhere in the lower extremity and/or the back or a degree of 90 is reached without pain. The angle of elevation was recorded using plastic goniometric. SLR with 70 degrees or more without pain was considered to be normal ${ }^{7}$. At the endpoint, the effect of ankle dorsiflexion, and maximal neck flexion were evaluated as well. After that the SLR repeated but with lumbar flexion by flexing the contralateral hip to 90 degrees, the angle of the SLR was also recorded. Crossed straight-leg raising test was performed. A positive crossed SLR is defined as the reproduction of sciatic pain in the symptomatic leg when passive SLR is performed on the asymptomatic leg ${ }^{11}$. Femoral stretching test was also performed by flexing the knee with the patient lying prone, pain in the anterior thigh and/or lumbar region indicates a positive test ${ }^{11}$. Neurological assessment for all patients was also done.

\section{RESULTS}

Table 1 shows the demographic features of the patients participating in this study. The mean age of patients was $33.2 \pm 8.46$ years, $55.7 \%$ of patients were males.

The main clinical features of the 70 patients with sciatica participated in this study are shown in Table 2.

Table 3 shows the results of the sciatic nerve stretch test and the femoral nerve stretch test for the 70 patients participated in the study. Sixty four patients had positive SLR test with angle less than 70 degrees.

Table 1: Demographic features.

\begin{tabular}{ll}
\hline Total no. & $\mathbf{7 0}$ patients \\
\hline Males & $39(55.7 \%)$ \\
Females & $31(44.3 \%)$ \\
Mean age & $33.2( \pm 8.46)$ \\
Mean duration of pain in weeks & $23.2( \pm 17.7)$ \\
\hline
\end{tabular}

Table 2: clinical characteristics of the studied group.

\begin{tabular}{|c|c|c|}
\hline \multicolumn{2}{|l|}{ Features } & $\begin{array}{c}\text { No. of patients (\%) } \\
30(42.9 \%)\end{array}$ \\
\hline $\begin{array}{l}\text { Duration } \\
\text { class }\end{array}$ & $\begin{array}{l}\text { Acute } \\
\text { Subacute } \\
\text { Chronic }\end{array}$ & $\begin{array}{l}30(42.9 \%) \\
17(24.3 \%) \\
23(32.9 \%)\end{array}$ \\
\hline \multicolumn{2}{|c|}{ Lumbar pain } & $53(75.7 \%)$ \\
\hline \multicolumn{2}{|c|}{ Buttock pain } & $45(64.3 \%)$ \\
\hline \multicolumn{2}{|c|}{ Rt. Sciatica } & $29(41.4 \%)$ \\
\hline \multicolumn{2}{|c|}{ Lt. sciatica } & $41(58.6 \%)$ \\
\hline \multicolumn{2}{|c|}{ Stress pain } & $35(50 \%)$ \\
\hline \multicolumn{2}{|c|}{ Mobility weakness } & $50(71.4 \%)$ \\
\hline \multicolumn{2}{|c|}{ Tendency to fall } & $30(42.9 \%)$ \\
\hline \multicolumn{2}{|c|}{ Numbness } & $41(58.6 \%)$ \\
\hline \multicolumn{2}{|c|}{ Gait abnormality } & $17(24.3 \%)$ \\
\hline \multicolumn{2}{|c|}{ Painful flexion \&/or extension } & $55(78.6 \%)$ \\
\hline \multicolumn{2}{|c|}{ Painful side bending } & $41(58.6 \%)$ \\
\hline \multicolumn{2}{|c|}{ Limited flexion } & $21(30 \%)$ \\
\hline \multicolumn{2}{|c|}{ Limited side bending } & $8(11.4 \%)$ \\
\hline \multicolumn{2}{|c|}{ Sensory deficit } & $23(32.9 \%)$ \\
\hline
\end{tabular}


The mean SLR angle degree was 47.8 degrees, and it was increased when the SLR performed after flexing the contralateral hip as shown in Table 4.

Table 5 shows the site of the pain induced by the SLR test. Lumbar pain was induced in $50 \%$ of the patients.

Table 3: Results of 1- Sciatic stretch test (SLRT) in the 70 patients and the augmentation or ameliorating tests in the 64 patients with positive SLRT. 2- Crossed SLRT and femoral stretch test in the 70 patients.

\begin{tabular}{lcc}
\hline Sciatic n. stretch & No. & Percent \\
\hline Positive SLRT (angle < 70) & $64 / 70$ & $91.4 \%$ \\
\hline $\begin{array}{l}\text { Positive ankle augmentation } \\
\text { Increased pain by neck flexion }\end{array}$ & $18 / 64$ & $95.3 \%$ \\
$\begin{array}{l}\text { Decreased pain by neck } \\
\text { flexion }\end{array}$ & $2 / 64$ & $3.1 \%$ \\
$\begin{array}{l}\text { Increased SLR angle by } \\
\text { contralat. hip flexion }\end{array}$ & $52 / 64$ & $81.3 \%$ \\
$\begin{array}{l}\text { Decreased SLR angle by } \\
\text { contralat. hip flexion }\end{array}$ & $6 / 64$ & $9.4 \%$ \\
$\begin{array}{l}\text { Crossed SLR test } \\
\text { Femoral n. stretch }\end{array}$ & $12 / 70$ & $17.1 \%$ \\
\hline Positive & $35 / 70$ & $50 \%$ \\
\hline
\end{tabular}

Table 4: Mean SLR angle degrees with and without contralateral hip flexion.

\begin{tabular}{lcc}
\hline \multicolumn{1}{c}{ SLR method } & $\begin{array}{c}\text { Mean } \\
( \pm S D)\end{array}$ & $\begin{array}{c}\text { p- } \\
\text { value }\end{array}$ \\
\hline $\begin{array}{l}\text { Mean SLR angle degree (64 } \\
\text { patients) }\end{array}$ & $\begin{array}{c}47.8 \\
( \pm 12.4)\end{array}$ & \\
Mean SLR degree with & 58.9 & $0.00^{*}$ \\
$\begin{array}{l}\text { contralateral hip flexion (64 } \\
\text { patients) }\end{array}$ & $( \pm 16.9)$ & \\
\hline
\end{tabular}

${ }^{*}=$ significant according to independent sample t-test.

Table 5: Pain sites induced by positive SLR test (64 patients).

\begin{tabular}{lccc}
\hline \multicolumn{1}{c}{ Pain site } & No. & Percent & $\begin{array}{c}\text { Positive ankle } \\
\text { effect }\end{array}$ \\
\hline lumbar pain & 32 & 50 & $31(96.8 \%)$ \\
leg pain & 27 & 42.1 & $25(92.5 \%)$ \\
$\begin{array}{l}\text { lumbar \& leg } \\
\text { pain }\end{array}$ & 5 & 7.9 & $5(100 \%)$ \\
\hline Total & 64 & 100.0 & \\
\hline
\end{tabular}

\section{DISCUSSION}

Seventy patients with unilateral sciatica were included in this study. Sixty four patients (91.4\%) elicited positive SLR test; the mean SLR angle was $47 \pm 12.4$ degrees.

In their study, Keer et al 1988, found that SLR was positive in $98 \%$ of patients. However, the test was only considered positive if it caused sciatic pain $^{12}$. In the case-control study of Demircan et al. 2002, the SLR was positive in $93 \%$ of their operated patient's' group, but the characterization of the positive SLR was not mentioned in the study ${ }^{13}$. Straight leg raising test is not necessarily limited even in patients with severe sciatica due to disc prolapse. One explanation for that is the presence of far lateral or minor disc protrusion ${ }^{7}$. Another possible explanation is that movement may not be transmitted to the root, and fibrous adhesion could explain this ${ }^{14}$.

Straight leg raising limitation is a mechanism that involuntarily protects the lower spinal nerves and the dura from painful traction. Under normal conditions, the lumbosacral nerve roots are relatively mobile$^{7}$. Straight leg raising places tension on the sciatic nerve and thereby pulls the sciatic nerve roots ( $L 4, L 5, S 1, S 2$, and S3) distally for few millimeters and stretches them near the anterior wall of the spinal canal ${ }^{15}$. In the presence of nerve roots irritation, such as by a herniated disk, further tension on the nerve root by straightleg raising will result in radiating pain in the $\operatorname{limb}^{1}$. If the nerve can't move freely, SLR on the affected side is usually markedly restricted ${ }^{15}$.

The patterns of pain that were induced by passive SLR fell into 3 well- defined groups: low back pain only, leg pain only, low back and leg pain. Previous studies have shown that the pattern of pain on passive SLR seems to be related to the position of the prolapsed disc. Within the horizontal axis, the protrusion may be situated in a central, intermediate, or lateral position. Patients with central protrusion tend to have low back pain only; patients with lateral protrusion tend to have leg pain only, while those with intermediate protrusion tend to have low back pain and leg pain ${ }^{16}$. The centrally protruded disc impinges the dura only, intermediate protrusion irritates the dura and nerve root, while the lateral protrusion irritates the nerve root alone ${ }^{8}$. So the production of back pain on passive SLR is probably due to dural irritation ${ }^{17}$. 
However alternative explanations are possible. O'Connell suggested that pain in the back on SLR may be related to the movement of the lumbar spine $^{18}$. Steindler suggested that back pain in patients who have spinal nerve compression might be due to referred pain along the posterior primary ramus $^{19}$. Subtle variations, such as adhesions of the dura or dural sheath in the spinal canal to the ligamentum flavum, annulus fibrosus, or the apophyseal joints capsules may all account for back pain during $\mathrm{SLR}^{20}$.

In this study, results showed that measurement of SLR was influenced by the position of the contralateral hip (flexed vs. extended); in that, a greater SLR angle occurred with the opposite hip flexed than with the opposite hip extended. Our finding was in agreement with a previously published paper by Cameron et al ${ }^{21}$. A possible explanation of this finding (as Goddard and Reid found) is that contralateral hip flexion decreases lumbar lordosis, as a result, the intervertebral foraminal space will become wider, and this lets the roots to run a more direct course outward, and appears to cause some slackening ${ }^{14}$. This will provide some relief of root pressure, and accordingly, higher SLR angle is required to induce pain. Our results point out the need to keep the contralateral hip fully extended during the SLR test.

The crossed straight leg raising test was positive in 12 patients $(17.1 \%)$. It points out severe impingement and it is almost always due to large disc herniation. Compared with SLR test, it has high specificity (88\%) but low sensitivity $(29 \%)$ for lumbar disc herniation ${ }^{4}$. The explanation of the crossed SLR test is that it involves the movement of the dura and contralateral root medially and distally when the unaffected limb is raised. It usually indicates a large more medially placed prolapse ${ }^{8}$.

Straight leg raising test is a neurodynamic test which doesn't only stretch neural tissue but also causes an increase in local muscle tone. Straight leg raising has been shown to activate hamstring and gluteal muscle when the hip flexion is held at maximally tolerated position ${ }^{22}$. Successful interpretation of SLR testing mandates the use of structural differentiation maneuvers during the test in order to highlight the rule of neural tissue in opposition to musculoskeletal tissue in making a change in the test outcome. Flexion of the cervical spine and dorsiflexion of the ankle are some examples of structural differentiation maneuvers ${ }^{9}$. These maneuvers increase tension exerted on the spinal dura and lumbosacral nerve roots. So the use of these maneuvers may increase the SLR diagnostic and predictive accuracy ${ }^{23}$. If the added neck flexion worsens the pain, it would be logical to think of a structure running from the occiput to beyond the knee; in such a case we exclude the hamstrings or sacroiliac joint as the cause of pain, but think of involvement of the dura matter.

Many previous reports considered ankle dorsiflexion and neck flexion as sensitizing maneuvers for $\operatorname{SLR}^{7,24,25}$. When we performed these 2 confirmatory tests on our patients we found that 61 patients (95.3\%) had a positive response on ankle dorsiflexion and 18 (28.1\%) patients had a positive response on neck flexion.

\section{CONCLUSION}

Straight leg raising test is positive in the majority of patients with sciatica. The patterns of pain that were induced by passive SLR fell into 3 welldefined groups: low back pain only, leg pain only, low back and leg pain. This could bear relation to the position of the prolapsed disc. The use of sensitizing maneuvers (ankle dorsiflexion, neck flexion) increases pain in patients with sciatica with positive SLR test, so we recommend the conduction of these maneuvers in patients with positive SLR. Measurement of SLR was influenced by the position of the contralateral hip (flexed Vs. extended), so we recommend measurement of SLR with contralateral hip kept in extended position.

\section{REFERENCES}

1. Dixit RK. Approach to the Patient with Low Back Pain. In: Imboden JB, Hellmann DB, Stone JH (eds) Current Rheumatology Diagnosis and Treatment, third edition. 2013. The McGraw-Hill Companies. United State of America. $p 86$.

2. Koes BW, van Tulder MW, Peul WC. Diagnosis and treatment of sciatica. BMJ, 334(7607): 1313-17, 2007.

3. Valat, JP; Genevay, S; Marty, M; Rozenberg, S; Koes, B. "Sciatica". Best Practice \& Research. Clinical Rheumatology 2010;24 (2): 241-52.

4. Deville WLJM, Windt DAWM, van der Dzaferagic A, Bezemer PD, Bouter LM. The test of Lasegue: systematic review of the accuracy in diagnosing herniated discs. Spine 2000; 25:1140-7. 
5. Van der Windt DA, Simons E, Riphagen II, Ammendolia C, Verhagen AP, Laslett M, et al. physical examination for lumbar radiculopathy due to disc herniation in patients with low-back pain (Review). Cochrane Database Syst Rev; 2:CD007431, Feb 2010.

6. Vroomen PC, de Krom MC, Knottnerus JA. Predicting the outcome of sciatica at short-term follow-up. Br J Gen Pract 2002; 52(475):119-23.

7. Xin SQ, Zhang QZ, Fan DH. Significance of the straight-leg-raising test in the diagnosis and clinical evaluation of lower lumbar intervertebral-disc protrusion. J Bone Joint Surg Am 1987; 69(4):517-22.

8. Urban LM. The straight-leg-raising test: a review*. J Orthop Sports Phys Ther 1981; 2(3):117-33.

9. Herrington L, Bendix K, Cornwell C, Fielden N, Hankey $\mathrm{K}$. What is the normal response to structural differentiation within the slump and straight leg raise tests? Man Ther 2008;13(4):289-94.

10. Koes BW, van Tulder MW, Thomas S. Diagnosis and treatment of low back pain. BMJ 2006; 332:1430-4.

11. Lawry GV, Fam AG. The spine. In: musculoskeletal examination and joint injection techniques. Mosby 2006; 115-6.

12. Kerr RS, Cadoux-Hudson TA, Adams CB. The value of accurate clinical assessment in the surgical management of the lumbar disc protrusion. J Neurol Neurosurg Psychiatry 1988; 51(2):169-73.

13. Demircan MN, Colak A, Kutlay M, Kibici K, Topuz K. Cramp finding: can it be used as a new diagnostic and prognostic factor in lumbar disc surgery? Eur Spine J 2002;11(1):47-51.

14. Goddard MD, Reid JD. Movements induced by straight leg raising in the lumbosacral roots, nerves and plexus, and in the intrapelvic section of the sciatic nerve. $\mathrm{J}$ NeurolNeurosurg Psychiatry 1965; 28(1): 12-8.
15. Charnley J. Orthopedic signs in the diagnosis of disc protrusion. Lancet 1951;1:186-92.

16. Edgar MA, Park WM. Induced pain patterns on passive straight leg raising in lower lumbar disc protrusion. J Bone Joint Surg 1974;56-B:658-67.

17. Wyke B. Neurological aspects of low back pain. In: Jayson MI (ed). Lumbar spine and back pain, 1977. New York: Grune and Stratlon. Pp. 189-256.

18. O'Connell JEA. Sciatica and the mechanism of the production of the clinical syndrome in protrusions of the lumbar intervertebral discs. British J. Surg 1943; 30:31527.

19. Steindler A. An analysis and differentiation of low back pain in relation to the disc factor. $\mathrm{J}$ Bone and Joint Surg 1947; 29:455-60.

20. Breig A, Troup JDG. Biochemical considerations in the straight leg raising test. Spine 1979; 4:243-50.

21. Cameron DM, Bohannon RW, Owen SV. Influence of hip position on measurements of the straight leg raise test. Ortho Sports Phys Therp 1994; 19(3):168-72.

22. Boyd BS, Wanek L, Gray AT, Topp KS. Mechanosensitivity of the lower extremity nervous system during straight-leg raise neurodynamic testing in healthy individuals. J Orthop Sports Phys Ther 2009; 39(11):780-90

23. Johnson EK, Chiarello CM. The slump test: the effects of head and lower extremity position on knee extension. Orthop Sports Phys Ther 1997; 26(6):310-7.

24. Boland RA, Adams RD. Effects of ankle dorsiflexion on range and reliability of straight leg raising. Aust $\mathrm{J}$ physiother 2000;46(3):191-200.

25. Frazier LM, Carey TS, Lyles MF, Khayrallah MA, McGaghie WC. Selective criteria may increase lumbar spine roentgenogram use in acute low back pain. Arch Intern Med 1989;149:47-50. 